\title{
Contextos organizacionais: a cultura como constituintes de identidade e imaginário
}

\section{Organizational contexts: culture as constituents of identity and imaginary}

\section{Caroline Delevati Colpo}

Professora dos Cursos de Comunicação Social da Universidade Feevale. <carolinecolpo@gmail.com>

\section{RESUMO}

Este trabalho constitui-se numa reflexão que busca discutir os contextos organizacionais e como suas culturas simbólicas interferem ou não na constituição da identidade e imaginários dos sujeitos que a integram. Com uma construção transdisciplinar, tem-se como opção de Método, o Paradigma da Complexidade, principalmente na tentativa de apreender/ entender/compreender a cultura simbólica presente na identidade e imaginários de sujeitos organizacionais. Nesta configuração espera-se trazer maior clareza para a explicação sobre os fenômenos dos contextos organizacionais na qual parte-se à compreensão que a cultura compartilhada tem a possibilidade de (re)construção constante e por sua vez alteram, interferem e (re)criam as identidades e os imaginários dos sujeitos organizacionais de forma recursiva.

Palavras-chave: Comunicação organizacional. Identidade. Imaginário.

\begin{abstract}
This work constitutes in a reflection that discusses the organizational contexts and how their symbolic cultures interfere or not in the formation of identity and imaginary of the individuals belonging to it. With a transdisciplinary construction, we have as option the Paradigm of Complexity, mainly in an attempt to learn/understand/comprehend this symbolic culture, present in the identities and the imaginary of organizational individuals. This configuration is expected to bring greater clarity to the explanation about the phenomena of organizational contexts in which we start to understanding that the shared culture has the ability to constant (re)construction, and in turn change, interfere and (re)create the identities and the organizational individuals' imaginary recursively.
\end{abstract}

KEYwords: Organization Communication. Identities. Imaginary. 


\section{Contextualização e procedimentos metodológicos}

- $\mathrm{H}$ ste estudo busca discutir contextos organizacionais e como as suas possibilidades

$\amalg$ culturais compartilhadas por processos comunicativos interfem ou não na constituição da identidade e imaginários dos sujeitos que a integram. Para tal pesquisa se utiliza como método de abordagem o Paradigma da Complexidade na procura de estabelecer diálogo entre as partes e seu todo, desfazendo limites entre diferentes áreas do saber com a sua característica transdisciplinar ${ }^{1}$ permitindo-lhes a comunicação ${ }^{2}$. Logo é preciso substituir os pensamentos que separam por pensamentos que unem, é preciso uma reforma no pensamento para que se substitua a linearidade pela transdisciplinaridade (Morin, 2008a). O pensamento complexo comporta e desenvolve diferentes tipos ou modos de inteligência, mas os supera pela importância de seu componente reflexivo. Do mesmo modo como a inteligência, o pensamento complexo também resolve problemas, mas propõe outros mais profundos, gerais, sem solução (Morin, 2007). Ele se autroproduz, no sentido de que quanto mais problematiza, mais se problematiza.

Este método auxilia a pensar por si mesmo para responder ao desafio da complexidade dos problemas, diferente da metodologia, que são as guias que programam as pesquisas (Morin, 2008a). O método não é o caminho, é a caminhada: ao invés de apenas separar, pode juntar; ao invés de só explicar, necessita compreender. O método não possibilitará uma resposta finalizada, uma conclusão. O método, como Morin (2008a) aponta, se torna uma forma de pensar na qual o pesquisador precisa integrar o espírito e o cérebro, ou seja, usar o método da complexidade como atividade cerebral, (caminhada) e como caminho, sem excluir nenhuma das possibilidades.

Três princípios, sugeridos por Morin (1991), auxiliam a entender o pensamento complexo utilizado neste texto: o princípio dialógico ${ }^{3}$ permite manter a dualidade no seio da unidade, associando, ao mesmo tempo, movimentos complementares e 
antagônicos; o princípio recursivo ${ }^{4}$ é um processo em que os produtos e os efeitos são, ao mesmo tempo, causas e produtores daquilo que os produziu, o sujeito é simultaneamente produzido e produtor, rompendo a ideia linear de causa/efeito, de produto/produtor, de estrutura/superestrutura, uma vez que tudo o que é produzido volta sobre o que produziu num ciclo autoconstitutivo, auto-organizador e autoprodutor; e, por fim, o princípio hologramático ${ }^{5}$, no qual não apenas a parte está no todo, mas o todo está na parte. Esses três princípios, aparentemente paradoxais, subvertem o espírito linear.

Na lógica recursiva, sabe-se muito bem que o que se adquire como conhecimento das partes regressa sobre o todo. O que se aprende sobre as qualidades emergentes do todo que não existe sem organização, regressa sobre as partes. Então pode enriquecer-se o conhecimento das partes pelo todo e do todo pelas partes, num mesmo movimento produtor de conhecimentos. Portanto a ideia hologramática está ligada à ideia recursiva, que por sua vez está ligada à ideia dialógica em parte."

(Morin, 1991, p. 90)

Este trabalho é resultado de uma pesquisa que busca a compreensão ${ }^{6}$ dos contextos organizacionais como um todo, tendo como parte, as identidades e imaginários dos sujeitos que a integram submersos nas suas possibilidades culturais. Espera-se com isso não separar e distinguir organizações de seus indivíduos, mas se busca discutilos como parte integrante de um mesmo sistema, tecidos conjuntamente em processo cultural e social. 


\section{Identidade no contexto organizacional}

No contexto organizacional o indivíduo é um ser social e, segundo Morin (2007), autoeco-organizado, extraindo energias físicas, biológicas, informação e organização do seu meio, constituindo-se nesse meio e dele dependendo. O indivíduo realiza-se numa cultura $^{7}$ que gera seus significados, mas dentro de uma cultura, também, permanece inacabado, quando não realiza todas as possibilidades de seus desejos, uma vez que a cultura, muitas vezes, o normatiza.

Sob esta perspectiva, o indivíduo tem a sua identidade social, que ao mesmo tempo em que permite a sua realização de identificação com o outro, também é capaz de subjugá-lo, excluí-lo e fragmentá-lo quando a sua geração de significados não condiz com a geração de significados do grupo a que pertence. Isto ocorre por que, muitas vezes, há um deslocamento, uma descentralização, uma perda de sentido dentro do grupo social a que o indivíduo pertence, ou seja, muitas vezes, para a realização de seus desejos, o indivíduo cria uma (re)significação da cultura na busca de outra produção de sentido dentro da mesma cultura. Esta produção de sentido no contexto cultural é capaz de (re)produzir uma nova identificação ou até uma nova identidade.

A identidade não é uma essência, nem um dado, nem um fato, tampouco é fixa, estável, coerente, unificada e permanente. A identidade é uma construção, um efeito, um processo de produção, uma relação. A identidade está ligada a estruturas discursivas e narrativas e a sistemas de representação social que são constantemente alterados. $\mathrm{Na}$ modernidade a identidade torna-se líquida ${ }^{8}$, múltipla, móvel, pessoal e/ou coletiva e sujeita a mudanças e inovações. A consciência de si passou a ser reconhecida dentro de contextos culturais, tornou-se possível refletir continuamente sobre os papéis e as possibilidades sociais e, quando necessário, distanciar-se da tradição, do estabelecido, do regulamentado. A identidade na modernidade foi ligada à individualidade e ao desenvolvimento de um único eu. 
Hall (2001) alerta para a "crise de identidade" do indivíduo contemporâneo, que vê seus quadros de referências abalados. As identidades modernas podem ser descentradas, deslocadas e fragmentadas e, às vezes, nem mesmo os elementos culturais dos grupos a que pertence o sujeito são capazes de lhe tirar da crise. Isto ocorre por que o indivíduo, considerado por Hall (2001, p. 12) como "sujeito pósmoderno" não possui uma identidade permanente, a "identidade torna-se uma celebração móvel", tornando-se questão de dúvida e incerteza.

É na dúvida e na incerteza gerada pela "crise de identidade" que o indivíduo se torna agente de (re)significação e auto(re)produção da sua cultura. Cada indivíduo assume identidades diferentes em diferentes momentos na tentativa de realização de seus desejos e acaba por articular identidades contraditórias que atuam e agem em diferentes direções. Entretanto, à luz do pensamento complexo, estas identidades contraditórias produzem consequências. As diferentes direções que a identidade do indivíduo assume são capazes de recriar a sua própria cultura e a cultura do grupo de que faz parte, desenvolvendo com isto uma relação hologramática complexa. É nesta relação hologramática (recriar) que vem do dialogismo (certeza/incerteza) da cultura para o indivíduo, através da capacidade de (re)identificação pelo próprio indivíduo, que a cultura e a identidade se recriam recursivamente.

Atualmente uma identidade plenamente unificada, completa, segura e coerente é uma fantasia. [...] à medida em que os sistemas de significação e representação cultural se multiplicam, somos confrontados por uma multiplicidade desconcertante e cambiante de identidades possíveis, com cada uma das quais poderíamos nos identificar - ao menos temporariamente."

(Hall, 2001, p. 13). 
Com essa flexibilidade, mobilidade, liquidez e transformação das identidades e, consequentemente, dos contextos culturais, tem-se uma sociedade em processo de mudanças constantes, rápidas e não permanentes. A solidez da identidade, que antes se amparava em elementos simbólicos estáveis e fixos, hoje se vê abrigada em um aparato simbólico flexível, instável e mutante que possibilita ao indivíduo diversas formas de identificação. Não se aborda aqui, a falta de referenciais simbólicos, eles permanecem e continuam a ser parte da cultura e da identidade, principalmente, quando se trata de contextos organizacionais e comunidades que se apoiam fortemente em referências simbólicas para criar identificação com seus indivíduos. Mas, com as novas práticas sociais interconectadas em um território único e global, estas referências simbólicas se (re)articulam em um processo de transformação constante. Com isso, (re)criam uma heterogeneidade cultural, com a (re)afirmação e resistência de algumas identidades, e dão margem ao surgimento de novas identidades, gerando assim novas possibilidades de identificação nos contextos culturais que estão inseridos os sujeitos, sejam eles grupos, organizações, comunidades ou a sociedade.

Toda essa relação de identificação com elementos simbólicos, criando e recriando significados para a identidade dos indivíduos, ocorre dentro de lugares com contextos culturais também cambiantes, híbridos e mutantes. Estes contextos, como já dito anteriormente, podem ser as organizações que os sujeitos integram. Os sujeitos, ao integrarem estas organizações, carregam consigo seus elementos simbólicos particulares, sua identidade e sua cultura, e, na menor relação que estabelecem com o outro, tudo pode ser alterado e (re)criado.

As organizações são possibilidades desenvolvidas pelos sujeitos e para os sujeitos, para que possam ter identificação e satisfazer suas ansiedades no que diz respeito às condições culturais e sociais. Estas organizações tornam-se lugares ${ }^{9}$ de identificação e identidade para os sujeitos à medida que produzem sentidos por processos comunicativos ${ }^{10}$. 
Na busca de uma produção de sentido, de certa forma, homogênea, alguns contextos organizacionais procuram se tornar "lugares" de identificação social de seus sujeitos, considerando, além da produção e reprodução de identidades individuais, principalmente, a produção e reprodução de identidades coletivas. Estas identidades coletivas podem ou não estar amparadas nos laços sociais que se estabelecem através das relações sociais ${ }^{11}$. A partir dos processos comunicativos que se estabelecem nas organizações e com a criação de uma identidade coletiva, estas podem ou não desenvolver a condição de se tornarem "comunidades realmente existentes" (Bauman, 2003), nas quais a identidade coletiva da organização prevalece, e/ou se tornam "comunidades imaginadas" (Bauman, 2003), nas quais as identidades individuais sobrepõem-se à identidade coletiva da organização. Desta forma, não se pode negar que muitas organizações na busca de tornarem comunidades ${ }^{12}$ realmente existentes podem gerar identificações para seus sujeitos, muitas vezes, apenas com base no imaginário que produzem de si para os sujeitos que as integram, uma vez que os imaginários podem, ou não, serem produzidos nos e/ou pelos contextos culturais organizacionais.

\section{Imaginário no contexto organizacional}

No sentido corrente, o imaginário é o campo (e o produto) da imaginação, entendida como faculdade criativa. A palavra é geralmente empregada como sinônimo de fictício, inventada e oposta ao real. Castoriadis (1982) diz que o imaginário é a capacidade de fazer como imagem algo que não é, nunca foi. Silva (2003) entende o imaginário como um reservatório que agrega imagens, sentimentos, lembranças, experiências, visões do real que realizam o imaginado e através de um mecanismo individual e/ou grupal sedimenta um modo de ver, de ser, de agir, de sentir, e de aspirar ao estar no mundo. $\mathrm{O}$ autor distingue o imaginado, uma projeção do irreal que poderá se tornar real, do 
imaginário que emana do real, estrutura-se como ideal e retorna ao real como elemento propulsor. O imaginário é complexo, uma vez que, necessita da relação dialógica entre real e irreal para se efetivar e da recursividade para existir, sendo que o real produz o irreal que, por sua vez, produz o real novamente.

O imaginário pode existir de forma individual, essencialmente por identificação (reconhecimento de si no outro), apropriação (desejo de ter o outro em si) e distorção (re-elaboração do outro para si) (Silva, 2003). No imaginário, o sujeito se consolida como o ser simbólico que quer ser. A relação entre sujeito e simbólico se efetiva por intermédio de formas imaginárias através do objeto de desejo do sujeito e suas identificações. Em outras palavras, o imaginário se constitui no referencial simbólico que está à disposição dos sujeitos. A forma de apropriação deste referencial vai depender da capacidade de identificação, apropriação e distorção do imaginário de cada sujeito.

Castoriadis (1982) alerta que o imaginário é o componente de todo o símbolo. Sob este viés, surge a necessidade de desenvolver uma compreensão sobre símbolo. Morin (2008a, p. 173) descreve o símbolo como sendo "a relação entre a própria realidade e a realidade designada como portador e evocador da presença e da virtude do que é simbolizado". O símbolo comporta uma relação de identidade com o que simboliza, suscita o sentimento de presença concreta do que é simbolizado e, na plenitude da sua força, constitui, numa só palavra ou figura, uma implicação ou concentração hologramática original da totalidade que torna presente. Assim, no extremo fervor da crença, a cruz comporta a paixão, a morte, a ressurreição e a mensagem redentora de Cristo, da mesma forma, no extremo fervor patriótico, a bandeira comporta a substância da mãe-pátria. A utilização de símbolos não depende de regras formais e pode, muitas vezes, tornar-se significante de uma estrutura social à qual pertence. Um símbolo é capaz de ressuscitar na sua rememoração e reconstituir uma representação, mesmo que em ausência. 
Geertz (1989, p. 144) contribui com o entendimento de Morin (2008a) quando expõe que

[...] os símbolos [...] relacionam uma ontologia e uma cosmologia com uma estética e uma moralidade: seu poder peculiar provém de sua suposta capacidade de identificar o fato com o valor no seu nível mais fundamental, de dar um sentido normativo abrangente àquilo que, de outra forma, seria apenas real. O número destes símbolos sintetizadores é limitado em qualquer cultura ..."

(Geertz, 1989, p. 144)

De toda forma, os símbolos apresentam e representam alguns dos fundamentos de uma cultura, refletem sobre as identidades e tem impactos sobre os imaginários. Percebe-se, com base nos conceitos expostos, que não há uma necessidade de contato físico para que o símbolo se comunique com o indivíduo. Muitos dos símbolos podem representar uma determinada cultura apenas pela sua rememoração, dependendo do valor simbólico ${ }^{13}$ que tem para os indivíduos.

Com isso o imaginário pode utilizar o simbólico ou o símbolo, não somente para exprimir-se, mas para existir, para passar do virtual a qualquer coisa a mais. Segundo Castoriadis,

[...] falamos de imaginário quando queremos falar de alguma coisa 'inventada' quer se trate de uma invenção 'absoluta' ('uma história imaginada em todas as partes'), ou de um deslizamento, de um 
deslocamento de sentido, onde os símbolos já disponíveis são investidos de outras significações que não as suas significações 'normais' ou 'canônicas' (...) Nos dois casos, é evidente que o imaginário se separa do real, que pretende colocar-se em seu lugar."

(Castoriadis, 1982, p. 154)

Sendo assim, o simbólico pressupõe o imaginário e nele se apoia. Isto não significa que o simbólico seja apenas o imaginário efetivo em seu conteúdo. O simbólico comporta quase sempre um componente real, mas que é apropriado de forma diferenciada pelos imaginários individuais.

O imaginário pode ainda ser social, estruturando-se principalmente pelo contágio simbólico, realizado pela interação e comunicação entre os sujeitos. O imaginário social pode ser constituído pela junção dos imaginários individuais, dentro de um contexto sócio-histórico. Neste caso, Castoriadis (1982) afirma que o imaginário social é sempre sócio-histórico, capaz de gerar processos de identificação a partir de significações sociais coletivas, mesmo que anônimas. $\mathrm{O}$ imaginário social é muito mais anônimo e inconsciente do que consciente, assim como, seus possíveis processos de identificação.

Sob esta perspectiva, o imaginário existe também nas organizações e pode-se encontrar de duas maneiras ${ }^{14}$ : individual (imaginário dos sujeitos que compõem a organização) e/ou imaginário social (imaginário formado pela organização composta de símbolos, valores e imagens). Uma vez que, tanto nos imaginários individuais, quanto nos imaginários sociais, os símbolos recriam-se como reais e irreais, corroborase com a afirmação de Silva (2003) que pelo imaginário o indivíduo se (re)constrói na cultura. $\mathrm{O}$ sujeito, com seu imaginário individual, coexistindo com o imaginário social, se constrói e se reconstrói dentro de uma cultura que pode ser também a cultura do contexto organizacional. Imaginário e cultura coabitam e coexistem no 
espaço organizacional e estão, constantemente, transformando-se em função das representações simbólicas dos sujeitos que compõem a organização.

Scroferneker (2009) argumenta que o sistema imaginário, por sua vez, é (re) produzido pela organização para viabilizar os sistemas cultural e simbólico. Citando Freitas (2000), complementa que o imaginário é o local da fantasia, ponto de partida de todas as significações, e que é compartilhado pelos membros de uma sociedade ou de um grupo social. Entretanto, o imaginário não surge do nada, não é espontâneo e de certa maneira pode ser induzido. Com isto, Scroferneker (2009) referencia Srour (1998), para explicar os imaginários construídos nos contextos organizacionais

As representações imaginárias que uma organização cultiva identificam quem é quem, demarcam praxes nem sempre explícitas, impõem precedências e formalidades compulsórias, regulam as expectativas e pautas de comportamento, e por fim, exigem cautela e aprendizagem por parte dos seus membros."

(Srour, 1998, p. 168)

Enriquez (1997, p. 35) corrobora com esta afirmação quando alega que no ambiente organizacional existe um "imaginário enganador". Este imaginário tenta prender os sujeitos nas armadilhas dos seus próprios desejos e carências. Faz com que, o imaginário da organização torne-se muito parecido com os imaginários dos sujeitos que a compõem, tornando-se, ao mesmo tempo, superpoderosa e protetora dos sujeitos, bem como, frágeis na tentativa de ocupar a totalidade do espaço imaginário, simbólico e cultural dos sujeitos através das identificações e representações. 
Enriquez (1997, p. 35) complementa enfatizando que há organizações que possuem "imaginário motor" e que permitem que seus sujeitos possam ser levados pela imaginação criativa dentro do ambiente de trabalho sem se sentirem reprimidos pelas regras imperativas. Há espaço para que cada sujeito troque suas experiências com os outros na medida da identificação e significação.

Porém, é necessário considerar que as organizações estão formadas por grupos de indivíduos que carregam consigo seus referenciais simbólicos, e que procuram expressar a sua identidade e seu imaginário dentro dos contextos organizacionais para o surgimento de novas identificação e criações de novos imaginários. Estas identificações dependem, em todas as instâncias possíveis, do imaginário dos sujeitos, ou seja, de como estes interpretam e reinterpretam os elementos simbólicos da organização, dos demais sujeitos, assim como, da cultura em que estes sujeitos estão imersos. Para a organização ser (re)interpretada depende do imaginário individual de cada sujeito, e, somente assim, irá (re)constituir o imaginário social. Entretanto, não se pode negar que as identificações dependem também do imaginário e da cultura que a organização (re)constrói em processo de criação e recriação simbólicas constantes - e oferece como outra possibilidades aos seus sujeitos, mas não como uma preponderante.

Assim, quando se entende as organizações com uma estrutura complexa, não é possível pensar em uma forma de imaginário (enganador e/ou motor) em detrimento do outro no contexto organizacional, ou de uma cultura mais homogênea, ou da realidade/irrealidade dos elementos simbólicos. Nas organizações complexas os sistemas imaginários, culturais e simbólicos (Enriquez, 1997), tanto da organização, quanto dos sujeitos, não têm limites de começo e de fim, eles se interpenetram, se misturam, se mesclam constantemente na (re)criação da organização, sua cultura, seus símbolos e imaginários. Para Srour (1998, p. 122) “toda organização comporta espaços variados [...]. E, em termos simbólicos, as relações de saber articulam uma espécie de 
palco em que se elaboram e difundem representações imaginárias". As organizações são, também, palcos de representações imaginárias e, com isso, podem ou não, criar um imaginário e uma cultura específica com base nos sujeitos que a integram.

O que se pode afirmar é que este processo de recriação da cultura, através da recriação dos símbolos e consequentemente do imaginário (tanto dos sujeitos como das organizações), teria dificuldade de se estabelecer sem uma efetiva relação entre organização e seus sujeitos. Esta relação se efetiva basicamente por um processo de comunicação. Se há uma cultura, ela precisa ser compartilhada. Se há identidades, elas precisam ser compartilhadas. Se há imaginário, ele precisa ser compartilhado.

\section{Apontamentos e algumas considerações}

Com a perspectiva da comunicação, muitos dos elementos culturais que circulam entre os indivíduos, através de suas relações sociais, transformam-se através de usos e (re)apropriações, tanto por parte de um grupo como por parte de um indivíduo. Para Morin (2008b), a cultura e a sociedade estão em relação geradora mútua, e nesta relação não se pode esquecer as interações entre os indivíduos, eles próprios portadores/transmissores de cultura, que regeneram a sociedade, a qual regenera a cultura. A relação entre cultura e grupos/organizações/sociedade/comunidades está em movimento recursivo, no qual, todos os elementos que compõem, tanto a cultura como os grupos, são produtores de uma nova ordem, e, além disso, produtos desta ordem estabelecida simultaneamente.

É, também, nos contextos organizacionais que os indivíduos criam e recriam a sua identidade individual e social, pois, ao mesmo tempo em que permitem a sua própria identificação com o outro, também é capaz de subjugá-lo, excluí-lo e fragmentá-lo. A identidade é uma construção, um efeito, um processo de produção, uma relação com o outro. Tanto a identidade social como a identidade individual são constituídas 
por compartilhamentos de informações e/ou pelos processos de comunicação. As organizações podem ser "lugares" ou "não-lugares" (Augè, 1994), dependendo da apropriação de cada sujeito, capaz de modificar, (re)construir ou (re)significar a identidade de seus membros de acordo com as culturas e a comunicação organizacional estabelecidas entre sujeito/organização e sujeito/sujeito.

Nesse mesmo cenário organizacional, o imaginário coexiste com a identidade e pode se encontrar de duas maneiras: individual (imaginário dos sujeitos que compõem a organização) e imaginário social (imaginário formado pela própria organização composta de símbolos, valores e imagens). Uma vez que, tanto nos imaginários individuais quanto nos imaginários sociais, os símbolos recriam-se como reais e irreais, e corrobora-se com a afirmação de Silva (2003) que, pelo imaginário, o indivíduo (re)constrói-se na cultura. Assim, o sujeito, com seu imaginário individual coexistindo com o imaginário social, se constrói e se reconstrói dentro de uma cultura que pode ser, também, a cultura organizacional. Imaginário e cultura coabitam e coexistem no espaço organizacional e estão constantemente transformando-se em função das representações simbólicas e identitárias dos sujeitos que compõem a organização. Desta forma, em um processo recursivo, pois os produtos e os efeitos da identidade e imaginários organizacionais são, ao mesmo tempo, causas e produtores daquilo que os produziu, o sujeito da organização é simultaneamente produzido e produtor, rompendo a ideia linear de causa/efeito, de produto/produtor, uma vez que tudo o que é produzido volta sobre o que produziu num ciclo autoconstitutivo, auto-organizador e autoprodutor. Este processo também pode ser entendido como hologramático no qual a organização está no sujeito e o sujeito na organização, da mesma forma que não apenas a parte está no todo, mas o todo está na parte. E por fim, a identidade e imaginário nos contextos organizacionais podem ser dialógicos, pois, são ao mesmo tempo, movimentos complementares e antagônicos, ora individuais, ora sociais ou 
não, mas essenciais para a cultura organizacional, na qual a cultura compartilhada pelos processos comunicativos é capaz de reconstruir a identidade e o imaginário dos sujeitos, e os sujeitos, por sua vez, são capazes de reconstruir a identidade e o imaginário da organização.

Guiada pelas motivações que deram início a esta reflexão, as incertezas aqui apresentadas, referentes a imaginário e identidades organizacionais, podem ser problematizadas em vários contextos, a fim de novos conhecimentos tornarem-se parte de um todo maior. Morin (2007) sugere que não há teoria sem brecha, não há pensamento sem risco, e é nisto que o pensamento desta pesquisa se apoia: em abrir novas brechas, no risco, na incerteza, na desordem para a geração de novos outros conhecimentos. Afinal, o que se espera de um processo de pesquisa e geração de conhecimento do conhecimento é subverter o pensamento linear, procurar, cada vez mais, por novas possibilidades de compreensões, implicando nelas subjetividades e afetividades, sem visualizar a finalização do processo de pesquisa.

\section{REFERÊNCIAS}

AUGÉ, Marc. Não-lugares: introdução a uma antropologia da supermodernidade. Campinas: Papirus, 1994.

BAUMAN, Zygmunt. Modernidade líquida. Rio de Janeiro: Jorge Zahar, 2001.

. Comunidade: a busca por segurança no mundo atual. Rio de Janeiro: Jorge Zahar, 2003.

CASTORIADIS, Cornelius. A Instituição imaginada da sociedade. Rio de Janeiro: Paz e Terra. 1982.

ENRIQUEZ, Eugène. A organização em análise. Petrópolis, RJ: Vozes 1997.

FREITAS, Maria Ester. Cultura organizacional. Rio de Janeiro: Editora FGV, 2000.

GEERTZ, Clifford. A interpretação das culturas. Rio de Janeiro: LTC, 1989.

HALL, Stuart. A identidade cultural na pós-modernidade. Rio de Janeiro: DP\&A, 2001.

MORIN, Edgar. Introdução ao pensamento complexo. Lisboa: Instituto Piaget, 1991.

. O método II: a vida da vida. Porto Alegre: Sulina, 2002.

. O Método III: o conhecimento do conhecimento. Porto Alegre: Sulina, 2008a. 
MORIN, Edgar. O Método IV: as ideias. Porto Alegre: Sulina, 2008b.

. O Método V: a humanidade da humanidade. Porto Alegre: Sulina, 2007.

. O Método VI: ética. Porto Alegre: Sulina, 2005.

SCROFERNEKER, Cleusa M. A. Comunicação e cultura organizacional: a complexidade dos diálogos '(in)visíveis'. Porto alegre: PUCRS, 2009.

SILVA, Juremir Machado da. As tecnologias do imaginário. Porto Alegre: Sulina, 2003.

SROUR, Robert Henry. Poder, cultura e ética nas organizações. Rio de Janeiro: Campus, 1998.

\section{NOTAS}

1 Por transdisciplinaridade entende-se desfazer os limites entre as áreas do conhecimento para que possam se comunicar e gerar novos conhecimentos (Morin, 2008a).

2 Entende-se a comunicação das partes com o todo, sendo ambas as organizações e as culturas, as identidades e os imaginários dos sujeitos.

3 Como exemplo, a ordem e a desordem podem ser concebidos em termos dialógicos. A ordem e a desordem são dois inimigos: um suprime o outro, mas ao mesmo tempo, em certos casos, colaboram e produzem organização e complexidade (Morin, 1991).

4 Como exemplo, a reprodução humana: o sujeito é produto de um processo de reprodução que é anterior a ele, mas uma vez produzido torna-se o novo produtor do processo que vai continuar (Morin, 1991).

5 Como exemplo, cada célula de um organismo contém a totalidade da informação genética deste organismo. (Morin, 1991).

6 Apropria-se do termo compreensão pelo olhar de Morin (2008a). A compreensão é o conhecimento que apreende tudo aquilo de que se pode fazer uma representação concreta, ou que se pode captar de maneira imediata por analogia, ou ainda a compreensão é o modo fundamental de conhecimento para qualquer situação humana implicando subjetividade e afetividade. A compreensão comporta uma projeção (de si para o outro) e uma identificação (com o outro). A compreensão comporta a distinção entre o eu e o tu em conjunção: é um "eu me torno tu permanecendo eu". Assim, por retorno de identificação, compreendese o que sente o outro por projeção do que sentiria em circunstâncias semelhantes e por retorno de identificação sobre si do sentimento projetado no outro. Amor e ódio são compreendidos por aquele que sabe o que é amor e ódio. Esta compreensão por vezes aparece como explicação. A explicação é um processo abstrato de demonstração logicamente realizada, a partir de dados objetivos, em virtude de necessidades casuais materiais ou formais e/ou em virtude de uma adequação a estruturas ou modelo. A compreensão compreende em função de transferências projetivas/identificatórias. A explicação explica em razão da pertinência lógica-empírica de suas demonstrações. 
7 Para entender uma determinada cultura, também em um contexto organizacional estabelecido, não se pode reduzi-la a particularidades. Geertz (1989) aponta que é necessário atentar para o comportamento dos sujeitos e fazê-lo com exatidão, pois é através do fluxo de comportamento - ou mais precisamente da ação social - que as formas culturais encontram articulação. Nesse sentido, para analisar a cultura não basta se apropriar dos elementos simbólicos que a constituem e organizá-los ou descrevê-los em padrões unificados, categorizados e formais. Quaisquer que sejam, ou onde quer que estejam, os elementos simbólicos que constituem determinada cultura necessitam ser analisados tendo como base a relação que estabelecem em meio às ações sociais que se desenvolvem em determinado contexto. O que se busca neste trabalho é um entendimento de como a cultura, através de seus elementos simbólicos, circula, interage, cria e recria identidades e imaginários, (re)estabelece relações sociais e participa do cotidiano dos indivíduos que integram nas organizações, servindo de pano de fundo ou como elemento norteador de suas ações e seus princípios.

8 Conforme descrição de Bauman (2001) para a compreensão de líquido na modernidade.

9 Segundo Augé (1994).

${ }^{10}$ Define-se como compreensão para processos comunicativos o compartilhamento, processo de trocas, intercâmbios e interações culturais, tornando-se necessário para sua efetivação conviver, buscar o outro através da relação, reforçar e renovar os laços sociais.

${ }_{11}$ Podem ser entendidas como relações de trabalho ou delas proveniente.

12 Estas comunidades têm o intento de criar relações, principalmente sociais, entre os sujeitos para que estes mantenham-se unidos de forma espontânea. Bauman (2003) entende que o estilo comunitário é casual, não precisa ser procurado, e muito menos construído. Entretanto, o autor sugere a impossibilidade da prática do sentimento de reciprocidade dos sujeitos para constituírem uma comunidade dentro de uma sociedade na qual as relações sociais se tornam cada vez mais líquidas.

${ }^{13}$ Para Morin (2008a) o valor simbólico é aquele que os objetos (pode ser considerado símbolo) têm em virtude dos modos pelos quais são estimados pelos indivíduos que os produzem e recebem, ou seja, podem ser aprovados, condenados, apreciados ou desprezados, não necessariamente tem relação econômica com o objeto, símbolo.

${ }^{14}$ Definição assumida para este trabalho.

Recebido em: 02 maio 2013

Aceito em: 08 mar. 2014

Endereço do autor:

Caroline Delevati Colpo <carolinecolpo@gmail.com>

Universidade Feevale

RS 239, 2755 - Vila Nova

93352000 Novo Hamburgo, RS, Brasil 